\title{
CHAPTER 91
}

\section{COMPREHENSIVE TIDAL STUDY OF THE ST, LAWRENCE RIVER}

\author{
J. Ploeg, Assoc. Research Officer, National Research \\ Council, Ottawa, Canada.
}

J.W. Kamphu1s, Asst. Research Officer, Natıonal Research Counc11, Ottawa, Canada.*

\section{ABSTRACT}

The St. Lawrence River is a major waterway connecting the Port of Montreal to the Atlantic Ocean. As is the case with so many natural rivers, extensive dredging has been necessary to provide adequate navigation conditions. About 100 years ago the Ship Channel of the St. Lawrence River was at several places only $10 \mathrm{ft}$ deep and $150 \mathrm{ft}$ wide; presently it has a minimum depth of $35 \mathrm{ft}$ and a minimum width of $800 \mathrm{ft}$. However, further 1mprovements are necessary, to meet present and future navigation requirements.

The Hydraulics Section of the National Research Council is studying improvement schemes by means of a hydraulic and a mathematical model of the St. Lawrence River from Montreal to Father Point, a distance of about 350 miles. The hydraulic model has been built to a horlzontal scale of $1: 2000$ and a vertical scale of $1 \cdot 120$. The mathematica 1 study uses a finite-difference approach, employing both exp11c1t and implicit computational schemes.

This paper describes the two studies and deals briefly with the merits of operating a mathematical and hydraulic mode 1 simultaneously.

\subsection{Introduction}

The St. Lawrence River (F1g. 1) is the largest river in Eastern Canada. Its drainage basin above Quebec City amounts to some 400,000 square miles, which is comparable to the areas of Great Britain, France and West Germany combined. The Great Lakes on the border between Canada and the United States are part of the St. Lawrence River System. They provide large natural storage areas and, together with the extensive hydroelectric developments, tend to regulate the river flow. The mean fresh water flow at Quebec City is $320,000 \mathrm{cfs}$, the

*) Now Asst. Professor, Queen's Unıversity, Kingston, Canada. 


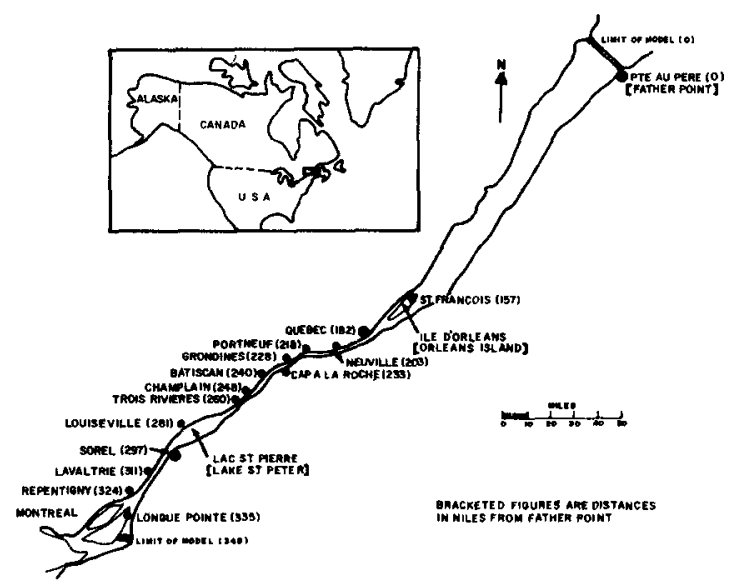

F1g. 1 St. Lawrence River

minimum recorded discharge $15190,000 \mathrm{cfs}$ and the maximum flow $1 \mathrm{~s}$ about $500,000 \mathrm{cfs}$, giving a ratio of 2.6 between the two extremes. Compared to other rivers, this ratio is very low; the ratio between the minimum and maximum flow of the Rhine for instance, is around 20 .

The tide propagates up the St. Lawrence River as far as Lake St. Peter, 750 miles inland from the ocean. Because of the large changes in the geometry of the river bed (F1g. 2), the tidal propagation is of a complicated nature. The mean tidal range at Father Point is $10 \mathrm{ft}$, at Quebec City $15 \mathrm{ft}$, and at Three Rivers $1 \mathrm{ft}$. The horizonta 1 tide at Father point has an average peak flow of 70 milion cfs, which $1 \mathrm{~s}$ reduced at Quebec City to about $1.5 \mathrm{mil1} 10 \mathrm{n}$ cfs.

The St. Lawrence forms the navigation route between the Atlantic Ocean and the Port of Montrea1, which together with the smaller ports of Three Rivers and Quebec City, handles approximately $36 \mathrm{~m} 11110 \mathrm{n}$ tons of cargo and $400 \mathrm{~m} 111 \mathrm{on}$ bushels of grain annually. In spite of the size of the St. Lawrence River, extensive dredging has been necessary at many places to provide an adequate navigation channel. To meet the requirements of modern navigation, further improvements are necessary. 


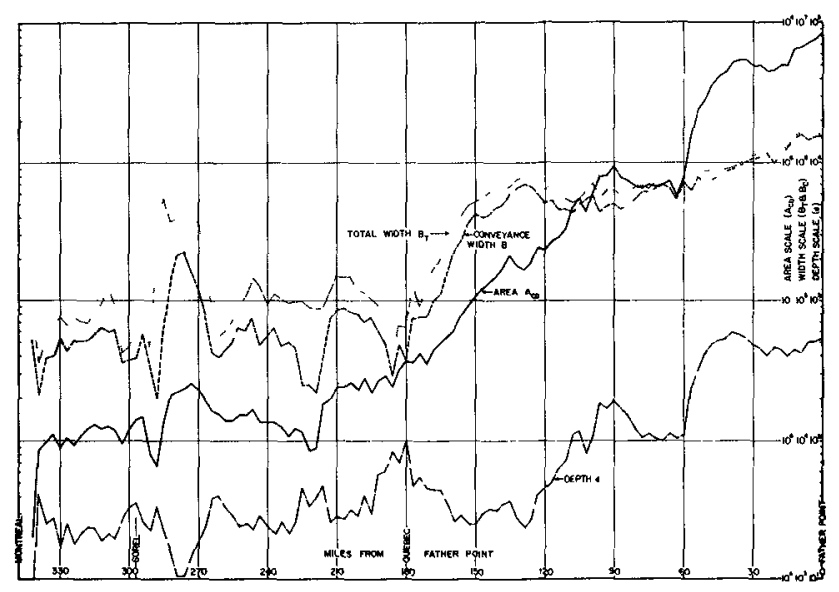

\section{Fig. 2 Representative River Dimensions}

The Department of Transport of the Canadian Government is responsible for the maintenance and improvement of the St. Lawrence Ship Channe1. This must be accomplished without adversely affecting the water levels in Montreal Harbour or any other region. The Hydraulics Section of the National Research Council was asked to undertake a comprehensive study of the tidal propagation on the St. Lawrence River and to investigate the effect of proposed improvement schemes on the tide and water levels throughout the river system. Because of the importance of the problem, it was decided to conduct simultaneously, studies on a hydraulic and a mathematical mode 1 .

\subsection{The Hydrau11c Mode1}

The Hydraulic Model of the St. Lawrence River at present comprises only the section from Montreal to Quebec City, a distance of 160 miles. Because of the size of the St. Lawrence River, the existing laboratory space was not sufficiently large to accommodate the entire model. While an extension to the bullding was under construction the 
first half of the model was completed and a temporary tida1 contro1 mechanism installed at Quebec City. This allowed the calibration of the first stage of the model and also some preliminary testing.

The model has a horizontal scale of $1: 2000$ and a vertical scale of $1: 120$. In addition to the practical considerations of available floor space and required accuracy of measurements, a number of other reasons dictated the choice of these scales. For example the Lake St. Peter area is extremely shallow with low current velocities and to obtain turbulent flow in the model in this region, a high distortion is desirable. However, at other locations, the cross-sectional area and shape of the river bed changes quite abruptly; one such area is just upstream of Quebec City. With too high a distortion, it may become 1mpossible to calibrate the model in reglons of strongly varying cross sections, since the flow pattern in the mode 1 would be drastically different from that of the prototype.

The distortion of about 17 , resulting from the choice of the horizontal and vertical scale of the St. Lawrence mode1, turned out to be close to the optimum. A smaller distortion would certainly have resulted in laminar flow conditions in Lake St. Peter, while a larger distortion would indeed have caused difficulties in the calibration of the model around Quebec City.

The first phase of the model construction was completed by the end of 1967 .

The calibration of this section of the model took approximately 6 months. Two sets of boundary conditions were used. In the first case, a mean discharge was used with a spring tide, whlle in the second case, a nearly mean discharge was combined with a neap tide. A more complete calibration will be carrled out next year, when the final section of the model from Quebec City to Father Point is completed. Calibration was achieved manly by varying the density of the artificial roughness pattern. The roughness elements consist of thin, 3/4" wide aluminum strips. Figure 3 shows some results of the final calibration tests. At all places the water elevations in the model are within $0.10 \mathrm{ft}$ of the recorded prototype water levels.

\subsection{The Mathematica1 Mode1}

During the course of the study several finitedifference mathematical mode1s, both explicit and implicit, were developed to simulate the propagation of the astronomical tides on the St. Lawrence River. Of the se only one will be described in this paper and for further detalls the reader is referred to previous publications by one of the authors (Refs. 1 and 2). 


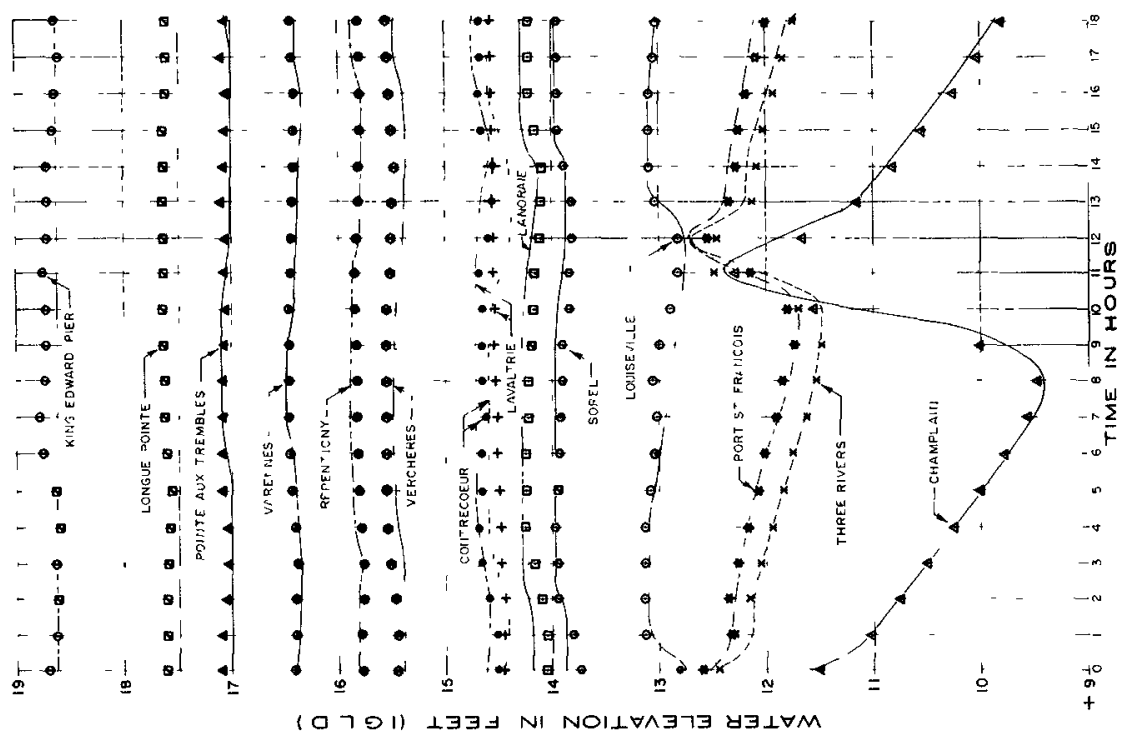

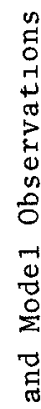

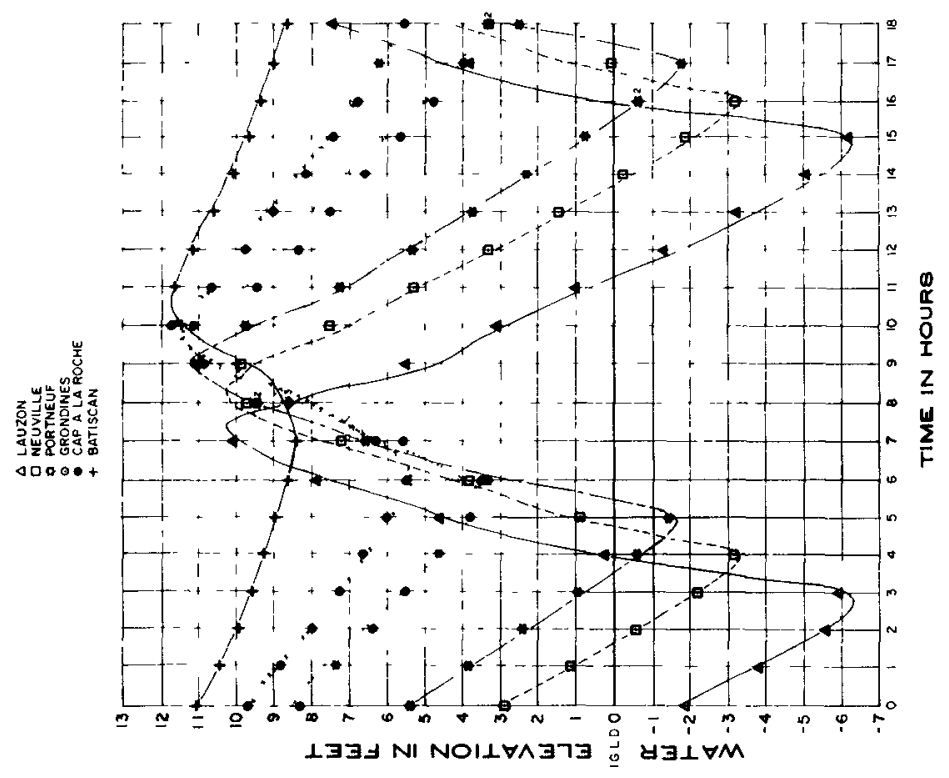

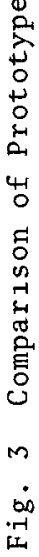


The model described here is an implicit finitedifference scheme with only one island taken into account. This is a reasonable simulation since the dimensions of the other islands are small compared with the river dimensions. The model limits are Father Point and Montrea 1 as in the hydraulic study. The river is divided into 204 longitudinal sections. Some of these sections are three miles long, while others, in regions where the river geometry varies considerably, are one mile long. The numbering scheme around Orleans Island is shown in Fig. 4; the section numbers have been circled and 52,62 and 72 are skipped in the numbering system. The remainder of the numbering scheme is self evident. Section 1 is at Father Point, Section 207 at Montrea1.

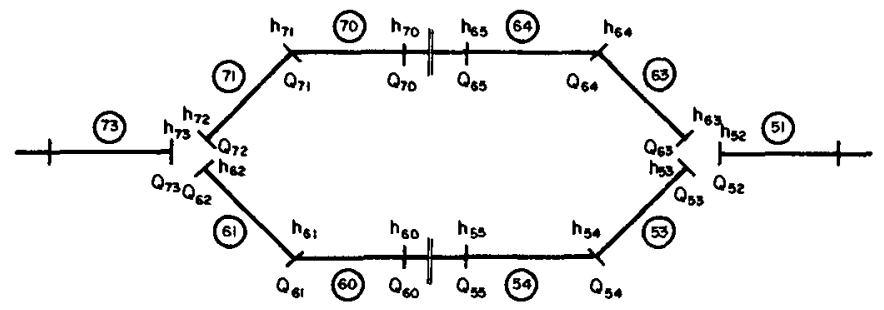

Fig. 4 Nomenclature at Orleans Island

3.1 Equations. The equations considered in this study are the equations of continuity and of motion for onedimensional unsteady flow in open channels. These may be written respectively as:

$$
\frac{\partial Q}{\partial x}+B_{S} \frac{\partial h}{\partial t}-\frac{Q_{T}}{d x}=0
$$




$$
\begin{gathered}
\frac{\theta_{1}}{g A} \frac{\partial Q}{\partial t}-\left(\theta_{1} \frac{\partial A}{\partial h}+\theta_{2} B_{S}\right) \frac{Q}{g A^{2}} \frac{\partial h}{\partial t}-\frac{\theta_{2} Q^{2}}{g A^{3}} \frac{\partial A}{\partial x} \\
=-\frac{\partial h}{\partial x}-\frac{Q|Q|}{C^{2} A^{2} d}
\end{gathered}
$$

where $Q$ is the river discharge, $h$ the water level with respect to a certain datum (IGLD-1955), QT the tributary inflow, BS the surface or storage width, $\theta_{1}$ and $\theta_{2}$ the momentum and energy coefficients of velocity distribution, A the conveyance area, $g$ the acceleration due to gravity, $C$ the Chezy friction factor and d the appropriate depth. It is evident that some simplifying assumptions have been made in the derivation of these equations.

These differential equations may be written as difference equations for each section:

$$
\begin{aligned}
& -h_{m}^{\prime}+\beta_{m}^{Q_{m}^{\prime}}+h_{m+1}^{\prime}+\alpha_{m} Q_{m+1}^{\prime}=\gamma_{m} \\
& \delta_{m} h_{m}^{\prime}-Q_{m}^{\prime}+\delta_{m} h_{m+1}^{\prime}+Q_{m+1}^{\prime}=\varepsilon_{m}
\end{aligned}
$$

where the dash refers to the values of $h$ and $Q$ at the new time level $t=t+\tau$, $\tau$ being the time step chosen and where $\alpha, \beta, \gamma, \delta$, and $\varepsilon$ are coefficlents which are functions of the known tidal conditions at $t i m e t=t$ and of the section dimensions resulting from the schematization process.

When these equations are written for each section and combined with usual conditions at the junction points and with the boundary conditions, $f_{1}(t)$ and $f_{2}(t)$, the water level variation at Father Point and the upland flow at Montreal respectively, a set of simultaneous equations resulting in a matrix as shown in Fig. 5 may be set up.

3.2 Schematization: In a finite-difference scheme as described here, the river has to be schematized into a number of sections each with its own constant dimensions. From the charts and from avallable dredging records 1 t was possible to discern two distinct levels, the chart datum level and the level above which the ground is never inundated (Fig. 6). The river widths at these two levels were determined, $\mathrm{B}_{\mathrm{CD}}$ is the width at chart datum, and $\mathrm{B}_{\mathrm{T}}$ the total width. $\mathrm{A}$ third width, $B_{C}$, was also taken at the 6 foot depth contour, the width of the conveyance channel. These widths were obtalned by planimetering the appropriate surface area for each section. In addition to these widths, the correct mileage from the reference point (Father Point), the crosssectional area below chart datum (total river volume in the 


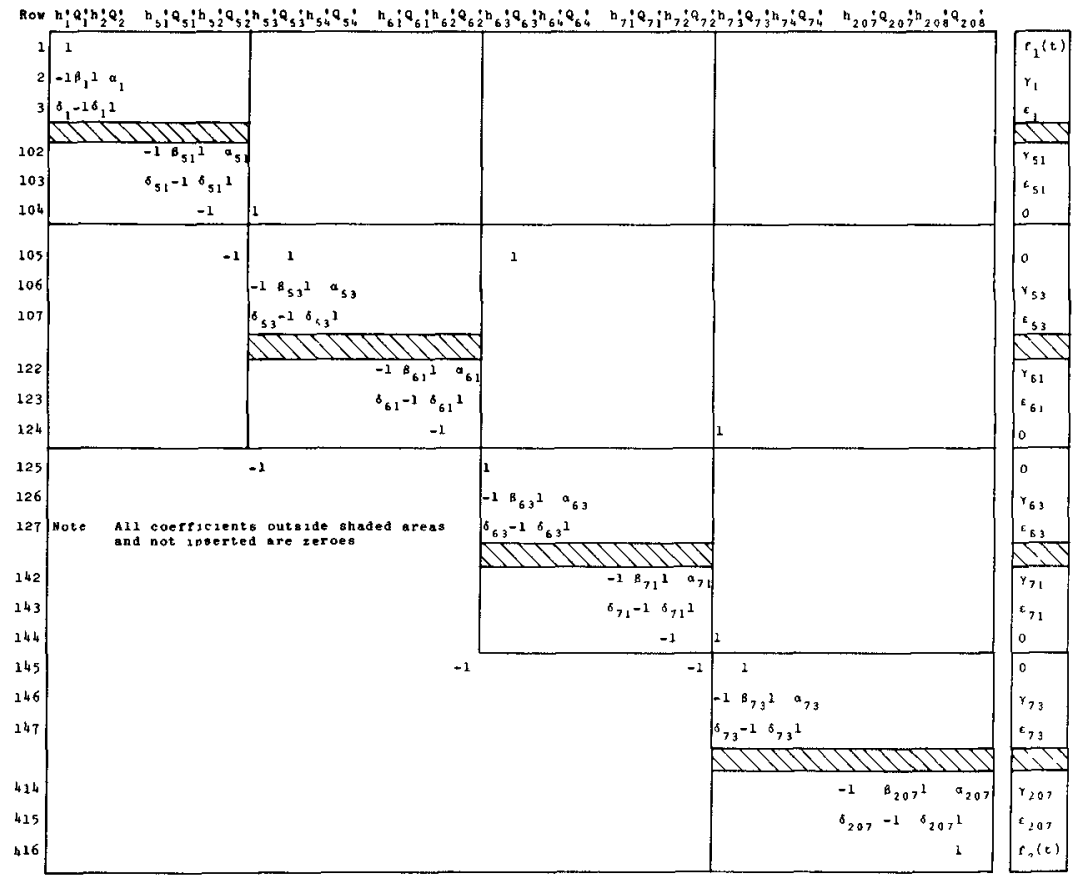

F1g. 5 Matrix Resulting from the Equations

section divided by the section length), the elevation of the chart datum with respect to IGLD, the maximum level of the shallow areas and the tributary discharge into the section were also obtained. Each river cross section was then simplified and represented in the model as shown in F1g. 7 .

3.3 Solution: The crux of an acceptable method of solution is the efficient evaluation of the large matrix in Fig. 5 which must be solved at every time step. The procedure followed has been outlined in detall in Refs. 1 and 2 , and is somewhat as presented by Dronkers in Ref. 3 . In essence, the matrix is reduced to upper triangular form and subsequently the solution proceeds by back-substitution. 


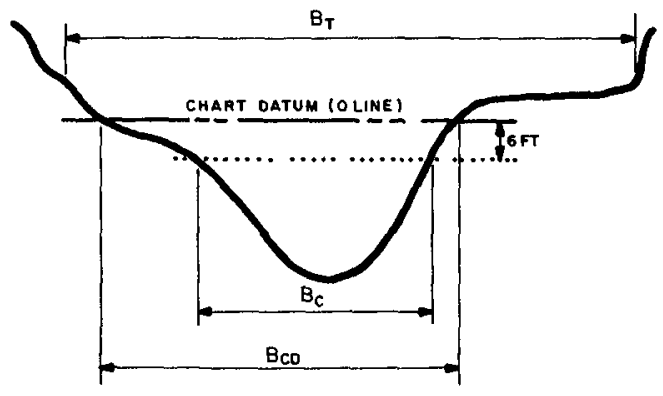

Fig. 6 Definition of Widths

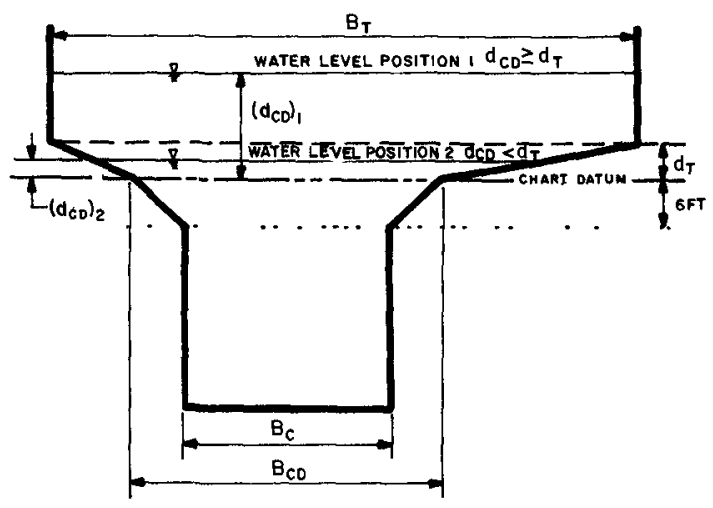

Fig. 7 Adopted Schematization

In the areas away from the island, all values in the matrix of Fig. 5 appear along the major diagonal. In this case it is possible to reduce Eqs. (3) and (4) to

$$
\begin{aligned}
& Q_{m}^{\prime}+q_{m} h_{m+1}^{\prime}+t_{m}^{Q_{m+1}^{\prime}}=s_{m} \\
& h_{m+1}^{\prime}+p_{m+1}^{Q_{m+1}^{\prime}}=r_{m+1}
\end{aligned}
$$


where:

$$
\begin{aligned}
& q_{m}=\frac{1}{\beta_{m}+p_{m}}, t_{m}=\frac{\alpha_{m}}{\beta_{m}+p_{m}}, s_{m}=\frac{\gamma_{m}+r_{m}}{\beta_{m}+p_{m}} \\
& p_{m+1}=\frac{1+\zeta_{m} t_{m}}{\delta_{m}+\zeta_{m} q_{m}}, r_{m+1}=\frac{\varepsilon_{m}-\delta_{m} r_{m}+\zeta_{m} s_{m}}{\delta_{m}+\zeta_{m} q_{m}}
\end{aligned}
$$

and where

$$
\zeta_{m}=1+\delta_{m} p_{m}
$$

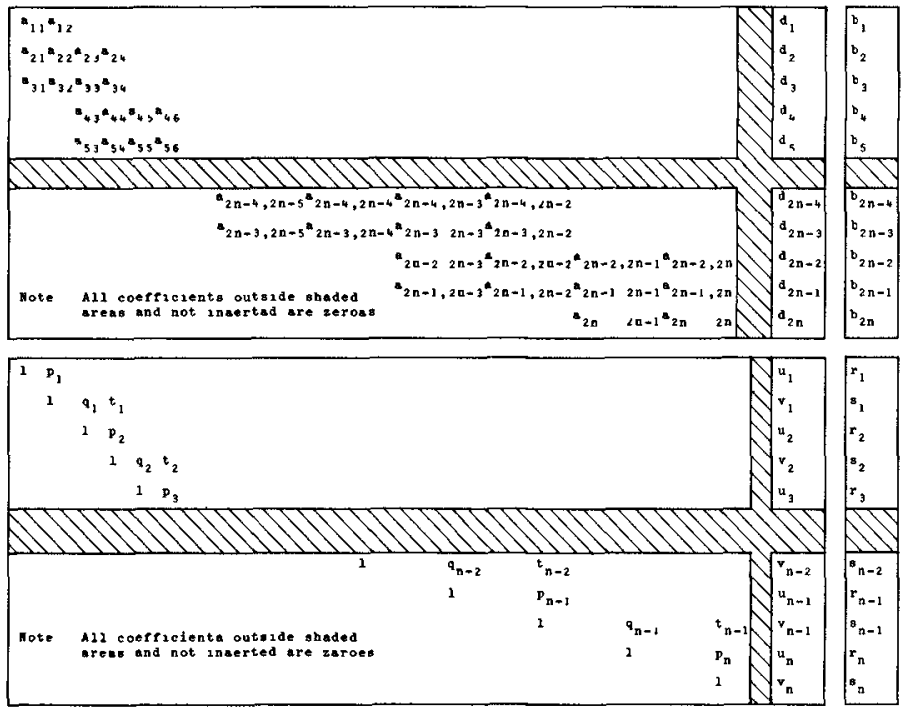

F1g. 8 Triangularization of a Matrix with an Additional Column

In the areas with junctions, the problem of triangularization is more complex since some values appear quite a distance away from the major diagonal. For the case where a value appears to the right and 
above the diagonal it is possible to extend the method developed above. Referring to Fig. 8 , the top matrix with an additional column denoted by $\mathrm{d}_{\mathrm{n}}$, may be reduced to the lower matrix using the relationships:

$$
\begin{aligned}
& q_{i}=\frac{a_{21,2 i+1}}{a_{21,2 i^{-a}} a_{1,2 i-1} p_{1}} ; t_{1}=\frac{a_{21,21+2}}{a_{2 i, 21} a_{21,21-1} p_{1}}
\end{aligned}
$$

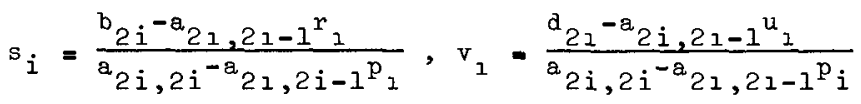

$$
\begin{aligned}
& p_{1+1}=\frac{a_{2 i+1,2 i+2}+\zeta_{1}{ }_{1}}{a_{21+1,21+1}+\zeta_{i} q_{1}} ; r_{1+1}=\frac{b_{21+1}-a_{2 i+1,21-1} r_{1}+\zeta_{1} s_{1}}{a_{21+1,21+1}+\zeta_{1}{ }_{1}} \\
& u_{i+1}=\frac{d_{2 i+1}-a_{21+1,2 i-1} u_{i}+\zeta_{i} v_{1}}{a_{21+1,21+1}+\zeta_{1} q_{i}} \\
& \zeta_{1}=-a_{2 i+1,2 i^{+a}} 2 i+1,21-1 p_{1} \\
& p_{1}=\frac{a_{12}}{a_{11}}, r_{1}=\frac{b_{1}}{a_{11}} \text { and } u_{1}=\frac{a_{1}}{a_{11}}
\end{aligned}
$$

When values of an additional row appear below the band, the matrix is first triangularized and these values subsequently eliminated as in Fig. 9, using the relationships:

$$
\begin{aligned}
& c=c_{2 n-1}+(-1)^{n} a_{n-1} L_{n-1} \\
& e=c_{2 n}+(-1)^{n} t_{n-1} L_{n-1} \\
& f=(-1)^{n} v_{n-1} L_{n-1}+\sum_{i=1}^{n-1}(-1)^{i_{w}} w_{1} \\
& g=(-1)^{n} s_{n-1} L_{n-1}+\sum_{i=1}^{n-1}(-1)^{1} p_{1},
\end{aligned}
$$

where

$$
\begin{aligned}
& L_{i+1}=(-1)^{i+1}\left(c_{2 i+2}-c_{21+1} p_{i+1}\right)+\left(t_{1}-q_{i} p_{1+1}\right) L_{1} \\
& p_{i+1}=(-1)^{1+1} c_{21+1} r_{1+1}+\left(s_{1}-q_{1} r_{1+1}\right) L_{1}
\end{aligned}
$$




$$
\begin{aligned}
w_{i+1}=(-1)^{1+1} c_{21+1} u_{i+1}+\left(v_{1}-q_{1} u_{i+1}\right) L_{i} \\
L_{1}=c_{1} p_{1}-c_{2} \\
P_{1}=c_{1} r_{1}-b_{2 n+1} \\
W_{1}=c_{1} u_{1}-d_{2 n+1}
\end{aligned}
$$

With these basic tools it is possible to solve the matrix in Fig. 5 and for illustration the successive steps will be given.
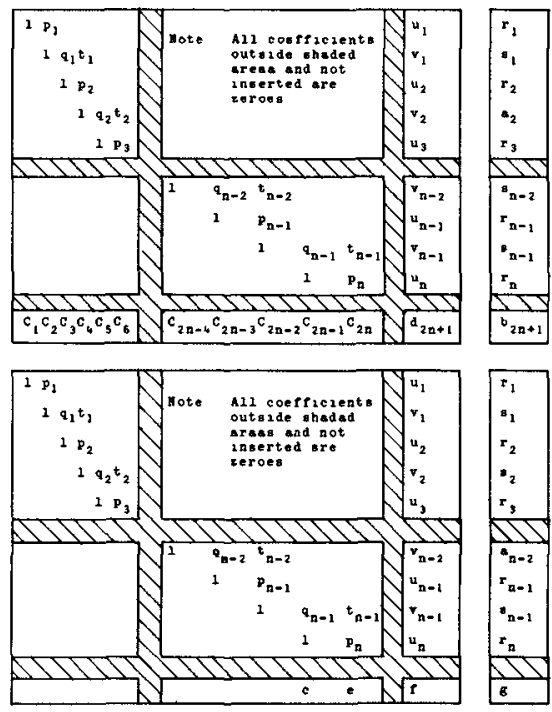

Fig. 9 Triangularization of a Matrix With an Additional Row

and (6). Triangularize to row 103 of Fig. 5 using Eqs. (5) 
105 may be easily eliminated. Using Eqs. (10), row 105 to 123 may be triangularized and again the $h_{62}$ term in row 124 may be eliminated. Eliminate the his term in row 125 using (11) and then eliminate the ch 62 and eQ 62 terms. Similarly, using (10) rows 125 to 143 may be triangularized, and the Q62 term in row 145 may be eliminated using (11). The remainder of the matrix is again a single channel and may be reduced to upper triangular form using (5) and (6). The result is the matrix in Fig. 10.

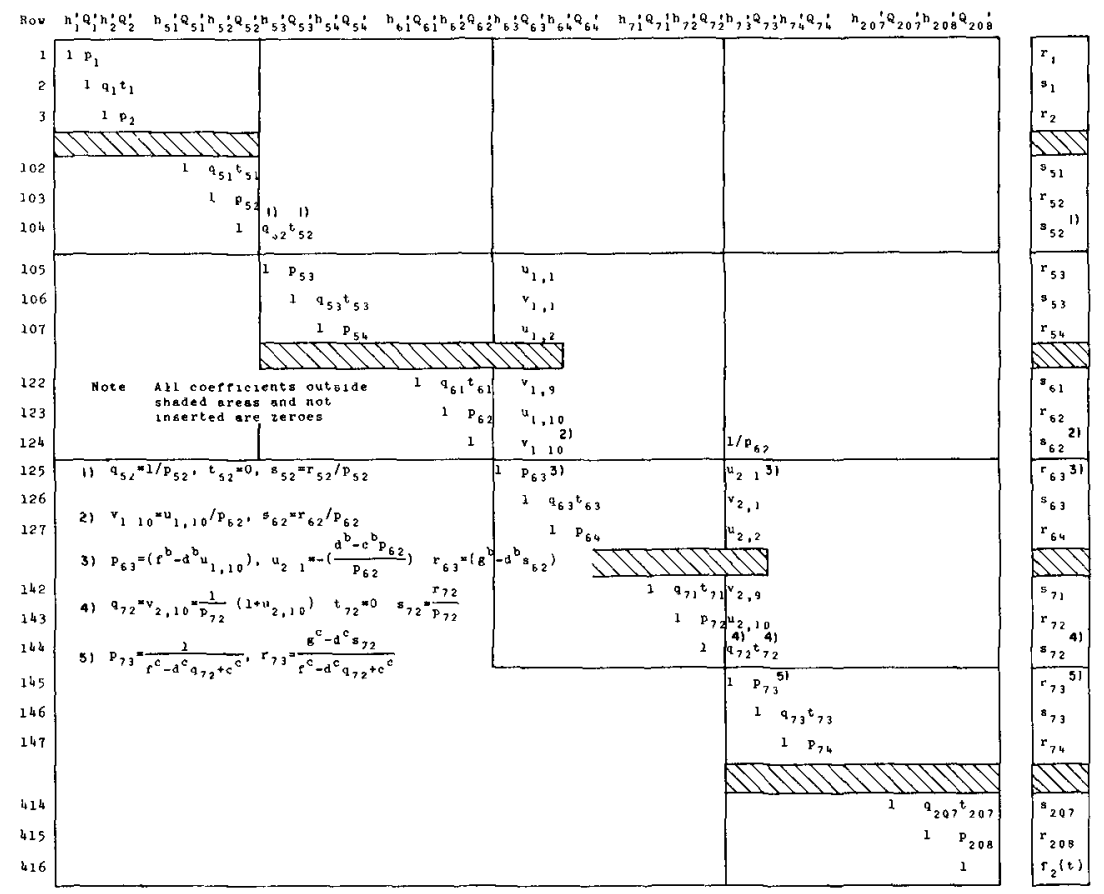

F1g. 10 Triangularized Matrix

The final step in the solution is one of back substitution. Since there is only one unknown in each row, all unknowns may be calculated beginning with Q208.

This method of solution is unconditionally stable, although in the elimination process, where it proceeds through the equations in numerical order, without due regard to the absolute value of the points used to eliminate each column, a type of mathematical instability could occur. In 
this particular problem, the growth of errors was not of a magnitude as to cause this type of instability.

The time required for a typical solution was 12 minutes on an IBM 360 model 50 computer. Th1s includes rather lengthy plotting routines.

Some results as they compare w1th observed prototype data are shown 1 in Figs. 11,12 and 13 , and here 1 may be seen that the model results correspond quite closely to the field results, the water levels being within $0.1 \mathrm{ft}$ and the time within 15 minutes. Water levels only could be compared since field current observations are at present not available.

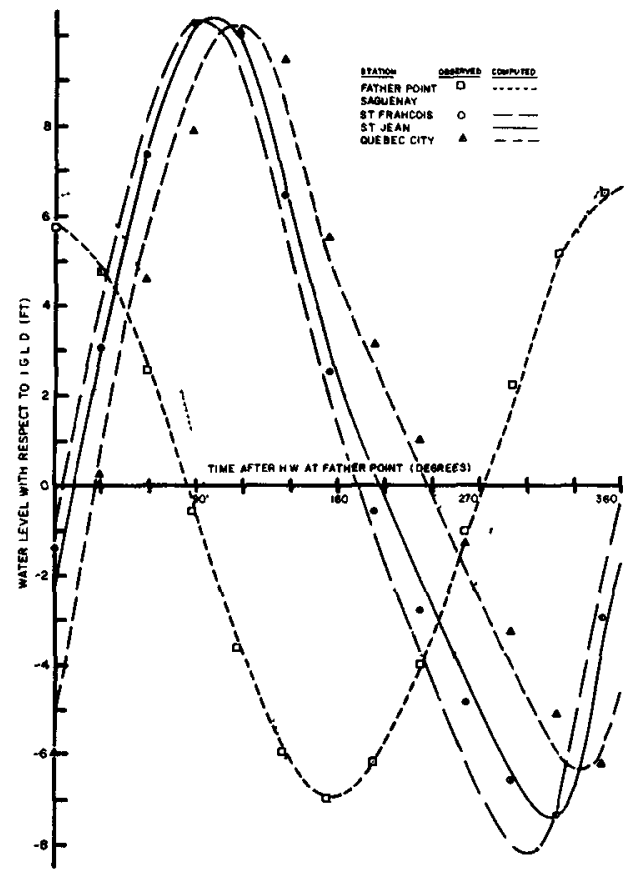

Fig.11 Comparison of Observed and Computed Water Leve1s 


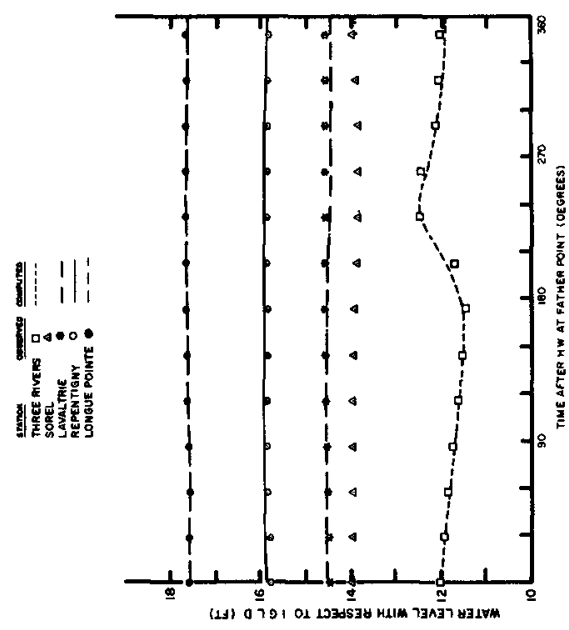

$\stackrel{m}{\rightarrow}$

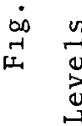

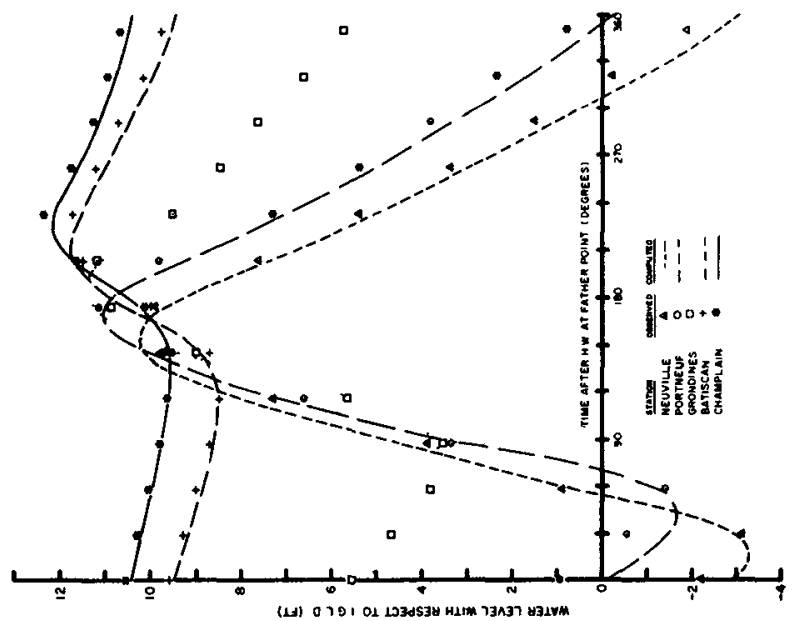

0
0
0
0
0
3
0
0
0
0
0
0
0
0
5
0
0
0
+
0
5
0
0
4
0
5
0
0
5
0
0
0
0
0 


\subsection{Testing Procedures and Results}

After the calibrations of the hydraulic and the mathematical model were completed, a series of tests was carried out to study the effect of some of the navigation improvement schemes. First of a11, the mathematical mode 1 had shown that the change in the tidal conditions at Quebec City as a result of most of the proposed plans was nil or very sma11. On1y the major improvement schemes, involving extensive modifications to the existing river conditions, affected the tidal propagation throughout the system. In such cases the present hydraulic mode1 can no longer be used without changing the downstream boundary conditions. The mathematical mode 1 was used to supply the new boundary conditions for the hydraulic model.

Another demonstration of the way in which the two models complement each other involves the generation of the tide at Quebec City in the hydraulic model. The basic input to the hydraulic model is the horizontal tide at Quebec City. This is accomplished with a variable inflow, which either supplies or withdraws the tidal discharge of up to $1.5 \mathrm{cfs}$. Since no actual discharge measurements are avallable for the calibration condition, the mathematical model supplies this input to the control circuit of the hydraulic mode 1 . A $10 \mathrm{ft}$ wide weir controlled by a feedback circuit connected to the vertical tide, acts as the final trimming device to give the exact tidal profile.

The first improvement schemes which were studied on both models, were the so-called Lake St. Peter plans. One of the plans under consideration, calls for the construction of dykes along the navigation channel through the lake. Lake St. Peter is a large shallow body of water, which now acts as an effective filter influencing the conditions upstream as well as downstream of the lake. In addition, the conditions in winter time on the St. Lawrence are very adversely affected by this shallow 1 ake.

The first series of tests included only the construction of dykes, without changing any of the other conditions. Obviously, this is mainly of academic interest since the new cross sectional area is only $1 / 5$ of the orlginal area and therefore the current velocities in the new channel will be unacceptably high. However, the tests show clearly the importance of Lake St. Peter in regard to its effect on the tidal propagation in the river. Figure 14 shows the envelopes of the high and low water elevations as observed on the hydraulic model and computed on the mathematical model for a spring tide with average upland flow, with and without dykes in Lake St. Peter. The water levels 
upstream of the lake have risen as much as $4 \mathrm{ft}$ at Sore 1 and about $2.5 \mathrm{ft}$ at Montreal, whlle just downstream of the lake the tidal range has increased considerably. The slight differences between the results of the hydraulic and the mathematical model are caused by the schematization of the delta at the upstream side of Lake St. Peter.

The second series of tests included not only the dykes along the channel, but also control structures which allow a certain amount of the flow to bypass the navigation channel over the north and south banks of the lake. The percentage of water to be diverted is governed by the maximum velocity allowed in the channel, which is in the order of $4 \mathrm{ft} / \mathrm{sec}$. The dotted line in Fig. 14 shows the water levels resulting from a test which included this diversion of flow.

The St. Lawrence Tidal Study has shown encouraging results so far. Having the two models operating simultaneously has indeed proven to be a great advantage and will certainly continue to be of assistance when the section of the St. Lawrence River from Quebec City to Father Point is included in the hydraulic model.

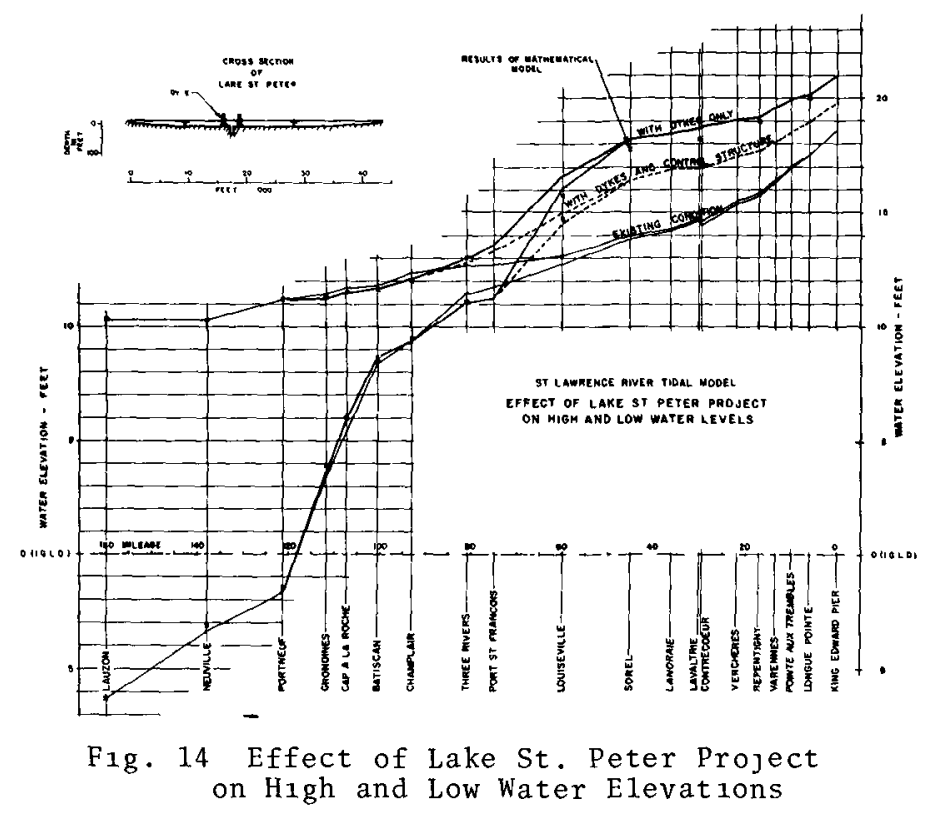




\subsection{Acknowledgments}

This study is sponsored by the Marine Hydraulics Branch of the Department of Transport.

The authors wish to express their appreciation for the excellent cooperation recelved from the Departments of Transport and Energy, Mines and Resources in the gathering of the required field data.

Also the cooperation of the Computation Centre and of the Instrument Laboratory of the National Research Council is gratefully acknowledged.

\subsection{Bibllography}

1. J.W. Kamphuis, 'Mathematica1 Mode1 Study of the Propagation of Tides in the St. Lawrence River and Estuary', Publication of the National Research Council MH-105 (to be published).

2. J.W. Kamphuis, 'Mathematica1 Mode1 Study of the St. Lawrence River', presented at the ASCE Hydraulics Division Specialty Conference, M.I.T., Boston, Aug. 1968 (to be published).

3. J.J. Dronkers, "Progress in Tidal Computations for Rivers, Coastal Areas and Seas', presented at the New York Conference of the ASCE, Nov. 67 (to be published). 